See discussions, stats, and author profiles for this publication at: https://www.researchgate.net/publication/351512596

\title{
A State-of-the-art Large-scale Laboratory Approach to Evaluating the Effectiveness of Geogrid Reinforcement in Flexible Pavements
}

Conference Paper · February 2021

CITATIONS

0

5 authors, including:

Hossein Alimohammadi

lowa State University

20 PUBLICATIONS 122 CITATIONS

SEE PROFILE

Junxing Zheng

lowa State University

84 PUBLICATIONS 1,172 CITATIONS

SEE PROFILE
READS

22

Vernon R. Schaefer

lowa State University

82 PUBLICATIONS 1,405 CITATIONS

SEE PROFILE

Some of the authors of this publication are also working on these related projects:

Effectiveness of Geotextile/Geogrids in Roadway Construction; Determine a Granular Equivalent (G.E.) Factor View project

Accelerated Load Testing of Geosynthetic Base Reinforced/Stabilized Unpaved and Pavement Test Sections View project 


\title{
A State-of-the-art Large-scale Laboratory Approach to Evaluating the Effectiveness of Geogrid Reinforcement in Flexible Pavements
}

\author{
Hossein Alimohammadi, Ph.D. student, ${ }^{2}$ Vernon R. Schaefer, Ph.D., P.E., M. ASCE ${ }^{2}$, \\ Junxing Zheng, Ph.D., M. ASCE ${ }^{3}$, David J. White, Ph.D., P.E., M. ASCE ${ }^{4}$, \\ Guangfan Zheng, M.S. ${ }^{5}$
}

${ }^{1}$ Civil, Construction and Environmental Engineering, Iowa State University, IA, USA, 50011; email: hosseina@iastate.edu

${ }^{2}$ Civil, Construction and Environmental Engineering, Iowa State University, IA, USA, 50011; email: vern@iastate.edu

${ }^{3}$ Civil, Construction and Environmental Engineering, Iowa State University, IA, USA, 50011; email: junxing@iastate.edu

${ }^{4}$ Ingios Geotechnics, Incorporated, P.O. Box 101, Northfield, MN, USA, 55057;

email: david.white@ingios.com

${ }^{5}$ Civil, Construction and Environmental Engineering, Iowa State University, IA, USA, 50011;

email: zgf@iastate.edu

\begin{abstract}
In this research, an Integrated Mobile Accelerated Test System (IMAS) was used to evaluate geogrids' reinforcement effects. The IMAS system consisted of a $5 \mathrm{ft}$ diameter and $3 \mathrm{ft}$ deep rigid box and an automatic loading frame to apply cyclic loads. A total of eight test configurations were constructed by varying geogrid types, geogrid locations in the base course, and base aggregate thicknesses. The IMAS performs cyclic load tests of pavement foundation sections to a large number of load cycles, which simulates vehicle-loading conditions expected during a pavement system's service life to evaluate the long-term performance of pavement structure. Testing results showed the effectiveness of geogrid reinforcement in the structural performance of pavements. Results show that biaxial and triaxial geogrids can decrease permanent deformation at the end of load cycles with an average value of 47 and 68 percent, respectively. Also, high-strength geogrids provide at least five psi pressure more than low-strength geogrids within the base course, which clarify that the high-strength geogrids can provide more confinement.
\end{abstract}

\section{INTRODUCTION, BACKGROUND, AND LITERATURE REVIEW}

In the United States, $64 \%$ of the roads are paved, and 95\% of them are flexible pavement. A conventional flexible pavement is constructed using an asphalt layer and granular materials on top of the subgrade layer. Weak subgrade and base course layers are usually the reasons causing the surface rutting under the accumulated load (Alimohammadi et al. 2020b). The pavement's design and construction over the weak and moist subgrade layer, which cannot provide sufficient strength, is always a problem for an engineer. One of the cost-effective methods to reduce the problem and improve flexible pavement behavior is the use of geogrid reinforcement (Alimohammadi et al. 2020). Additionally, geogrids are an environmentally friendly product that has been studied and used as reinforcement for the past two decades. Geogrids provide reinforcement to the pavement structure and offer a number of advantages, including reducing rutting damage, increasing the 


\section{(쇼 Geosynthetics Conference}

resilient modulus, and improving the drainage of the pavement. With the application of using the geogrids, the base course layer's thickness can be reduced, and the service life of the pavement can be extended (Han et al. 2008; Siekmeier and Casanova 2016). These benefits of geosynthetic reinforcement in the pavement are provided by the lateral restraint, separation, and geosynthetics tensioned membrane effect. Due to the load spreading over a wider area on top of subgrade in geosynthetic reinforced sections, vertical stresses transferred through the geosynthetic reinforced base onto subgrade are lower than the unreinforced sections. Geosynthetics can also decrease subgrade stress by absorbing shear stresses. (Zornberg 2017).

To evaluate the effectiveness of the geogrid reinforcement in flexible pavements, several factors should be considered, including geogrid location/depth, geogrid stiffness, geogrid aperture and rib shape, hot mix asphalt thicknesses, base aggregate quality, stiffness thicknesses, and subgrade stiffness (Alimohammadi et al. 2020a). Geogrids are commonly used within or at the bottom of the unbound aggregates to enhance the performance of a flexible base layer or the railroad ballast layer (Cuelho and Perkins 2017; Zornberg and Gupta 2010). Many studies introduced tests performed on large-scale or in-service geogrid-reinforced pavement sections and investigated the effects of the factors as mentioned above in geosynthetic reinforcement applications (Al-Qadi et al. 1994, 2011; Qian et al. 2013; Saghebfar et al. 2016). The results indicate that geogrids are effective in improving the stiffness and stability of the reinforced pavement structures and reducing the accumulated permanent deformation. The results suggest that the effectiveness of geosynthetics reinforcement is more notable on soft subgrade soil. The optimal geosynthetic layer location has been investigated in many investigations and recommended by some researchers to put within the upper one-third of the base layer; however, for the thinner aggregate layer, the reinforcement is recommended to locate the interface of the aggregate and subgrade layer. Also, it was determined that double reinforcement layers led to the better improvement regardless of the geogrid type plus the triangle geogrid provides better improvement compared to the biaxial geogrid with similar tensile moduli (Abu-Farsakh and Chen 2011).

In this research, a large-scale experimental test plan was developed using the Integrated Mobile Accelerated Test System (IMAS) system to evaluate the reinforcement effects of geogrids on pavements' structural benefits. A total of eight test configurations were constructed by varying geogrid types, geogrid locations in the base course, and base aggregate thicknesses, and the effects of these variables were studied on the resilient modulus, deflection, and permanent deformation results of the pavement foundation. The test configurations, the procedure of the tests, some details of the performed tests, and the results are discussed in the following sections.

\section{TEST SECTIONS, CONFIGURATIONS, AND SENSORS}

In this section, test sections, configurations, sensors, and procedures of performing the tests are explained.

Test sections. Eight test sections were performed to evaluate the pavement behavior using different geogrid types and under different locations: GE0, GE1, GE2, GE4, GE5, GE7, GE12, and GE15. GE0 was the control section, so no geogrid was installed in this section. Biaxial geogrid was used in GE1, GE2, GE5, and Triaxial geogrid was used in GE4, GE7, GE12, and GE15. For GE1, GE2, GE4, and GE12, the geogrid products were placed at the interface of the base course layer and the subgrade layer; for GE5 and GE7, the geogrid was installed at the middle of the base 


\section{(쇼 Geosynthetics Conference}

course layer. Also, both light-duty and heavy-duty geogrid products were used in the test as well. The details for the test sections are shown in Figure 1 below.

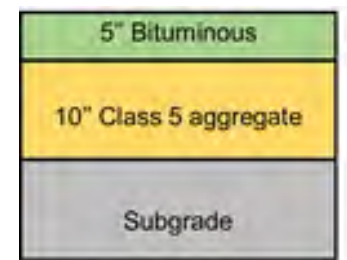

Section GE0

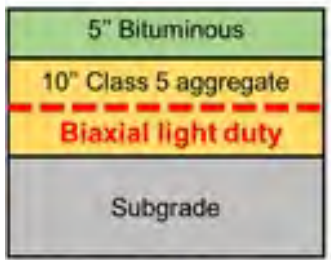

Section GE5

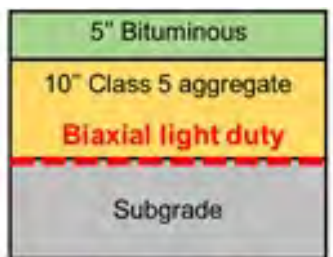

Section GE1

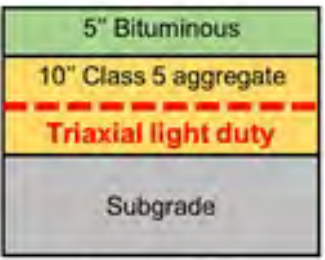

Section GE7

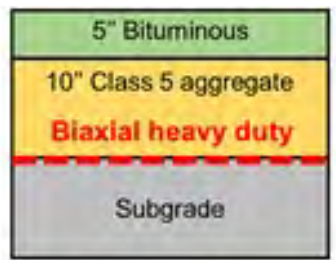

Section GE2

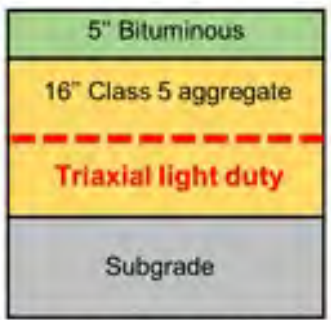

Section GE15

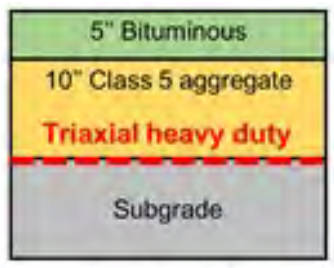

Section GE4

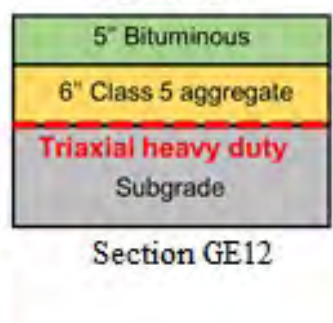

Figure 1. IMAS laboratory test sections

Configurations. The IMAS equipment and section are shown in Figure $2 \mathrm{a}$ and $\mathrm{b}$, and is used to perform the laboratory tests. The IMAS (Ingios Geotechnics 2020) was developed to mimic roadway systems' field loading conditions in a large-scale laboratory system wherein the conditions can be more easily controlled. The IMAS performs a cyclic load test with a large number of load cycles, which simulates vehicle-loading conditions on the pavement foundation. The IMAS can also help determine the resilient modulus, deflection, permanent deformation of the pavement so that the pavement system's service life and the long-term performance of the pavement structure can be evaluated. The IMAS device has a square base container, where the depth is three feet, and the length is five feet. Boundary effects and simulation of the natural soils' stiffness are controlled through the use of rigid walls and a foam layer. The load plate system or the hydraulic actuator is above the device's center to provide the repeated loading during the test. All the sensors are connected to the acquisition system, and the results can be recorded during the test for up to one million cycles. With the use of the IMAS equipment, eight laboratory tests were performed with different parameters. 100,000 cycles of random loading were simulated for each test section, and the test data such as the permanent deformation, strain, and pressure were recorded by the instrumentations like pressure cell and strain gauges.

Sensors. A lot of information can help compare and evaluate the reinforced pavement's behavior with different types of geogrids and determine the optimal placement location of the geogrid. To compare the pavement performance between each test section, it is necessary to record the permanent deformation, the stress at both the subgrade and base layer, as well as the strain behavior on the geogrid rib in different directions. These measurements can help to understand the mechanism for the geogrid and pavement. 


\section{(®A) Geosynthetics Conference}

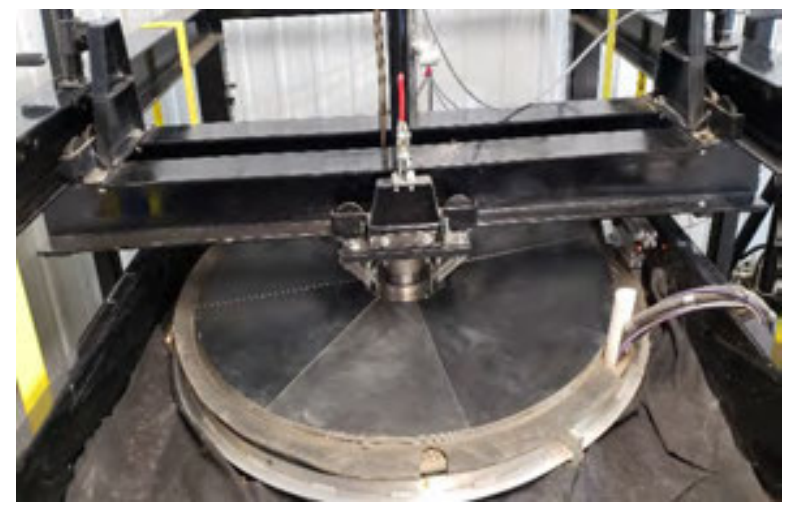

a)

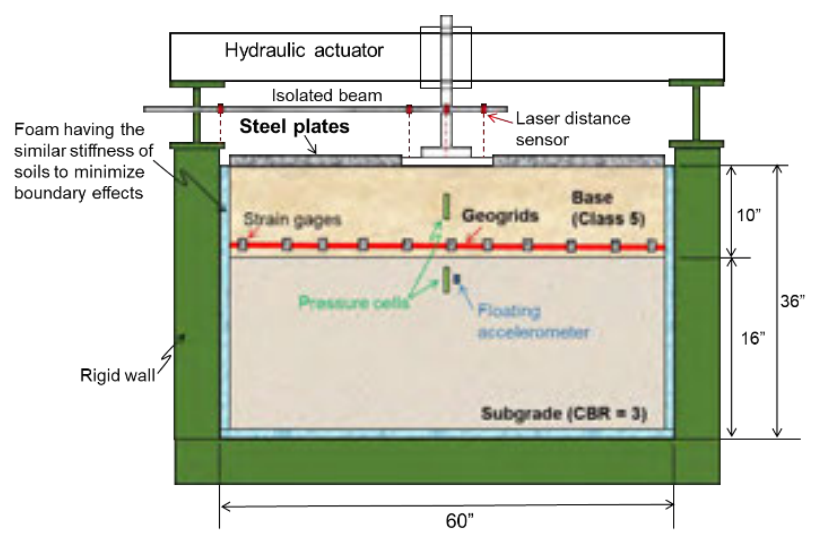

b)

Figure 2. a) Integrated Mobile Accelerated Test System for laboratory test, b) The test configuration in the IMAS device

Three instrumentations were selected according to the literature review, the data type, and the cost. The laser Linear Variable Differential Transformer (LVDT) was used to measure the deformation occurring on the top plate; two types of strain gauges were used to measure the strain behavior on the biaxial and triaxial geogrid rib, and a pressure cell was used to record the pressure. These instruments are shown in Figure 3.

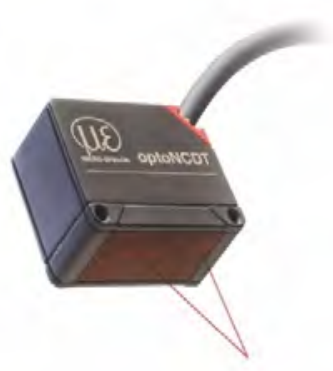

a)

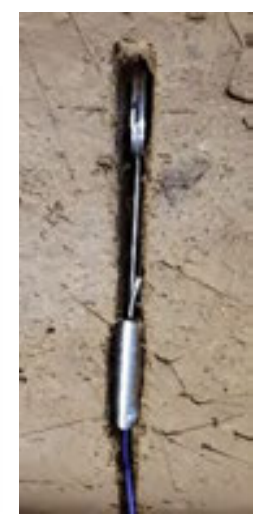

b)

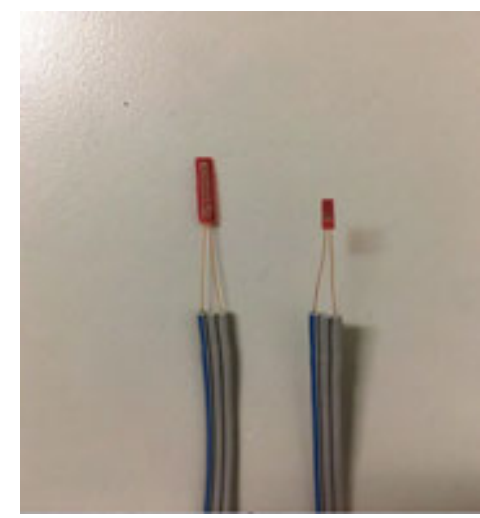

c)

Figure 3. The Instrumentations including a) Laser LVDT, b) pressure cells, c) strain gauges

\section{PROCEDURE OF PERFORMING THE TESTS}

The following Tensar geogrids were used in the laboratory tests: Light Duty Biaxial - Tensar BX1100, Heavy Duty Biaxial - Tensar BX1200, Light Duty Triaxial - Tensar TX130s, and Heavy Duty Triaxial - Tensar TX7. Class 5 aggregates, which are normally used for driveways and the base of construction projects, were used for the aggregate base layer. A silty clay subgrade soil with $\mathrm{CBR}=3$, representative of common subgrade soil conditions in Minnesota, was used. To achieve $\mathrm{CBR}=3$, the subgrade was prepared at a target moisture content of $16.6 \%$. 


\section{(冈ㅛ Geosynthetics Conference}

Subgrade preparation. The subgrade soil was added layer by layer; each layer was less than 15 inches in height to reach a uniform condition. A 50-lb drop hammer, compaction soil hammer, was used to provide compaction after adding each layer. To keep the surface flat, a tamper was used as well after each compaction. Finally, after cleaning the surface, a spirit level tool was used to measure and level the surface. Steps of subgrade preparation are illustrated in Figure 4a.

Base layer preparation. After subgrade preparation, the geogrid was placed at the subgrade surface in some sections, as illustrated in Figure $4 \mathrm{~b}$. Then the aggregates were placed above the geogrid layer. A rake was used to level the surface. After leveling the surface, a 6.5 HP plate compactor was used to provide the compaction on the base layer for three minutes. Steps of base preparation are illustrated in Figure 4c. To make sure the geogrids at the interface position will get the maximum involvement and interlocking with the aggregates, a layer of aggregate with a thickness of one inch was placed at the top of the subgrade surface. Then the geogrid was placed at the top of this thin layer, and then base materials were placed and compacted in the tests.

Surface layer preparation. A double layer of steel simulated the asphalt surface, which provides an equivalent weight of the real asphalt surface. The loading plate was set in the middle of the container. Each layer of steel has seven pieces of fan-shaped steel to cover the surface of the base material. Setting the steel surface installation is illustrated in Figure 4d. A thin foam layer was placed between the steel and the base layer to provide friction and protection. The final step was to connect all the sensors to the acquisition system, illustrated in Figures 4e and $\mathrm{f}$.

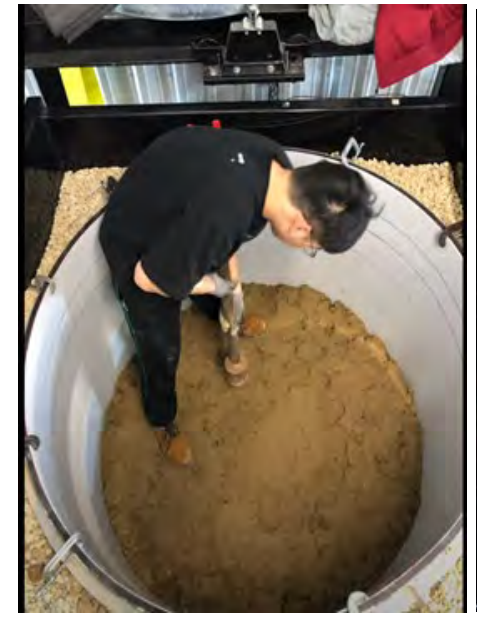

a)

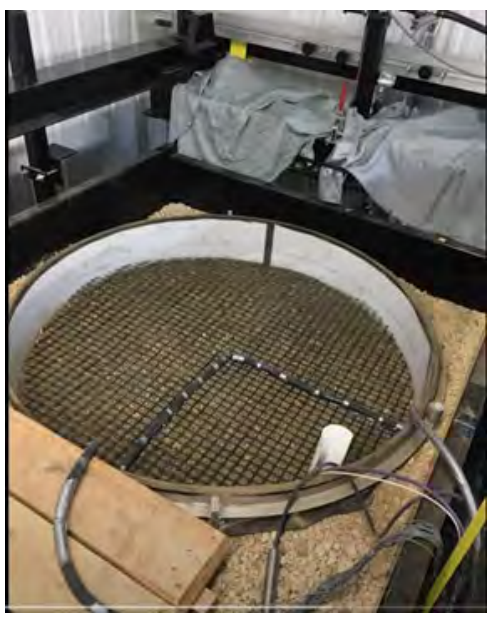

b)

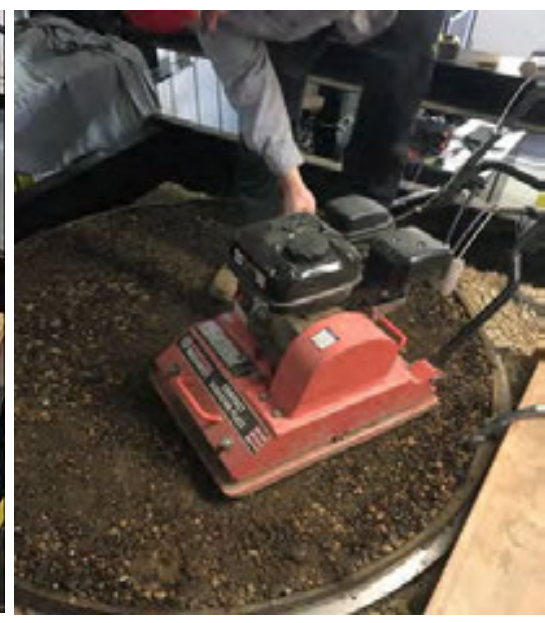

c) 


\section{(冈ㅛ Geosynthetics Conference}

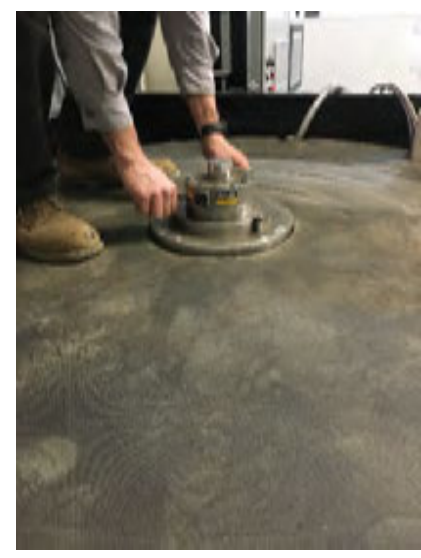

d)

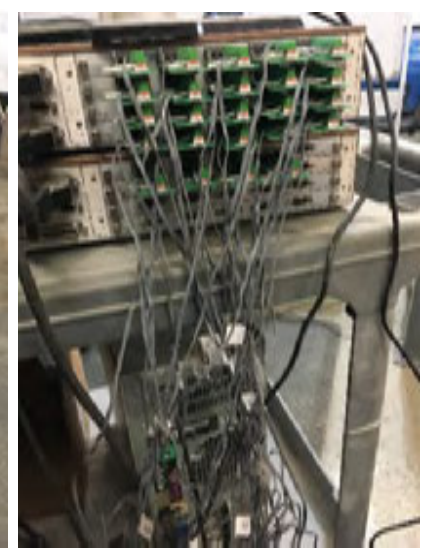

e)

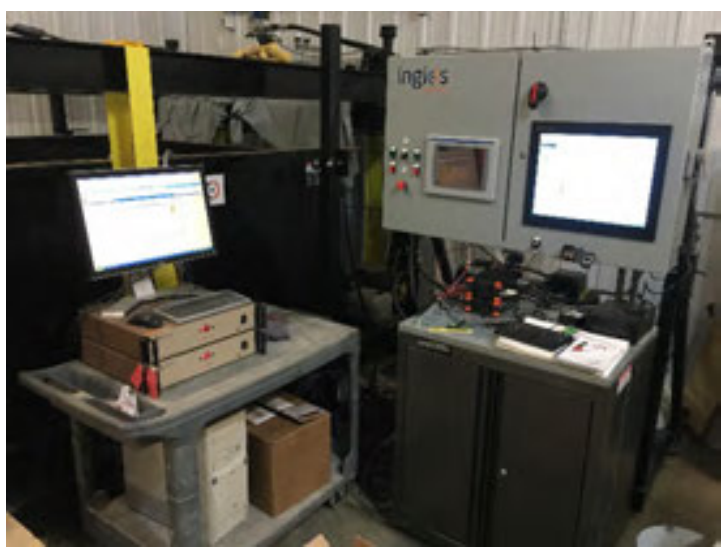

f)

Figure 4. Illustration of the a) subgrade preparation, b) setting geogrids, c) base layer preparation and compaction, d) surface layers preparation, $e$ and $f$ ) setting the data logger

\section{RESULTS AND ANALYSIS}

Figures 5 and 6 illustrate the strain gauge results of biaxial and triaxial geogrids for reinforced sections under the tests' compaction loading steps, respectively. From the results, it can be seen that during the application of compaction loads, the results of strain gauge in biaxial geogrids have fluctuation and reached higher peak values than triaxial geogrids, which gradually increase to get the maximum value of strains. Also, the residual strain in triaxial geogrids is less than biaxial geogrids.

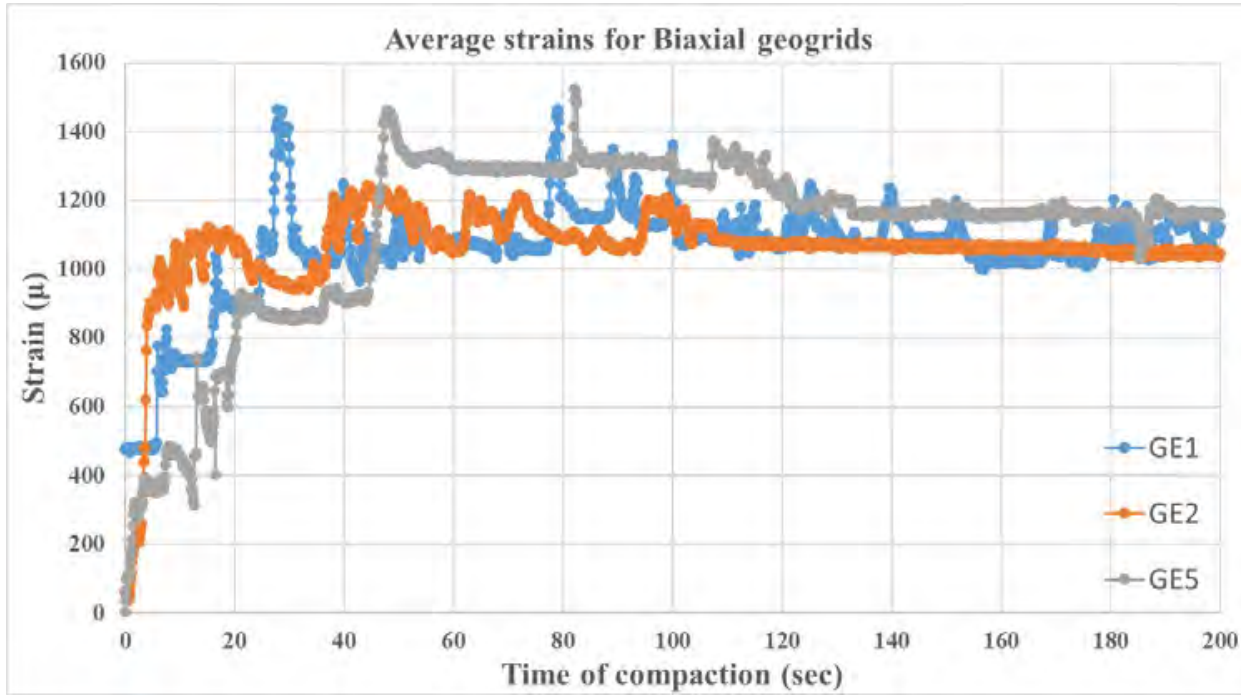

Figure 5. Average strains in the compaction part for Biaxial geogrids 


\section{(®A) Geosynthetics Conference}

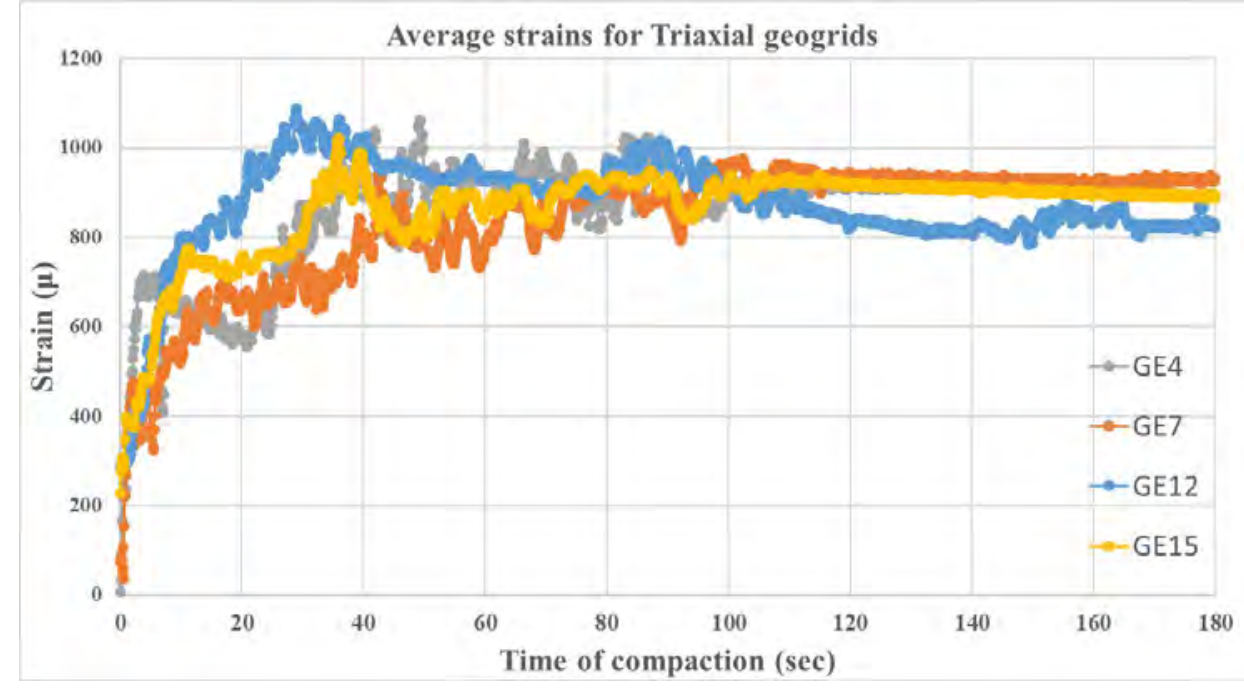

Figure 6. Average strains in the compaction part for Triaxial geogrids

Figure 7 illustrates the permanent deformation results of Triaxial and Biaxial geogrids. The increase in the pavement structure's service life has been commonly defined by the application of the Traffic Benefits Ratio (TBR). The TBR is described as the ratio of the number of load cycles to achieve a particular rutting depth in the reinforced section over an unreinforced section with exactly corresponding thickness, loading characteristics, and material properties. From the results, it can be seen that the triaxial geogrids perform much better than biaxial geogrids in reducing the permanent deformation of the sections for the same cyclic load numbers and increasing Traffic Benefit Ratios (TBR) values of the sections.

Two pressure cells were used for each test, one located on top of the subgrade and the other located on top of geogrid in the base aggregate layer to measure the value of pressure developing in both aggregate and subgrade layers in the tests. Figures 8 a to h show comparisons of both pressure cells in all eight sections performed in this study, and it can be seen from the results that the test sections with the heavy-duty geogrid always have higher pressure cell data reading than the light-duty geogrids. For the overall earth pressure cell results, except for GE4 and GE7 in figure $8 \mathrm{c}$ and e, respectively, the test sections have similar trends: the earth pressure cell data was increasing as the loading occurred, both in the subgrade and base course layer, but the increasing rate and magnitude are higher in base course layer than the subgrade layer. From the results in figure 8 it is obvious that under the same location, the maximum pressure in GE1 with the lightduty geogrid is 10 psi; however, the maximum pressure in GE2 with the heavy-duty can reach 15 psi. 


\section{(冈ㅛ Geosynthetics Conference}

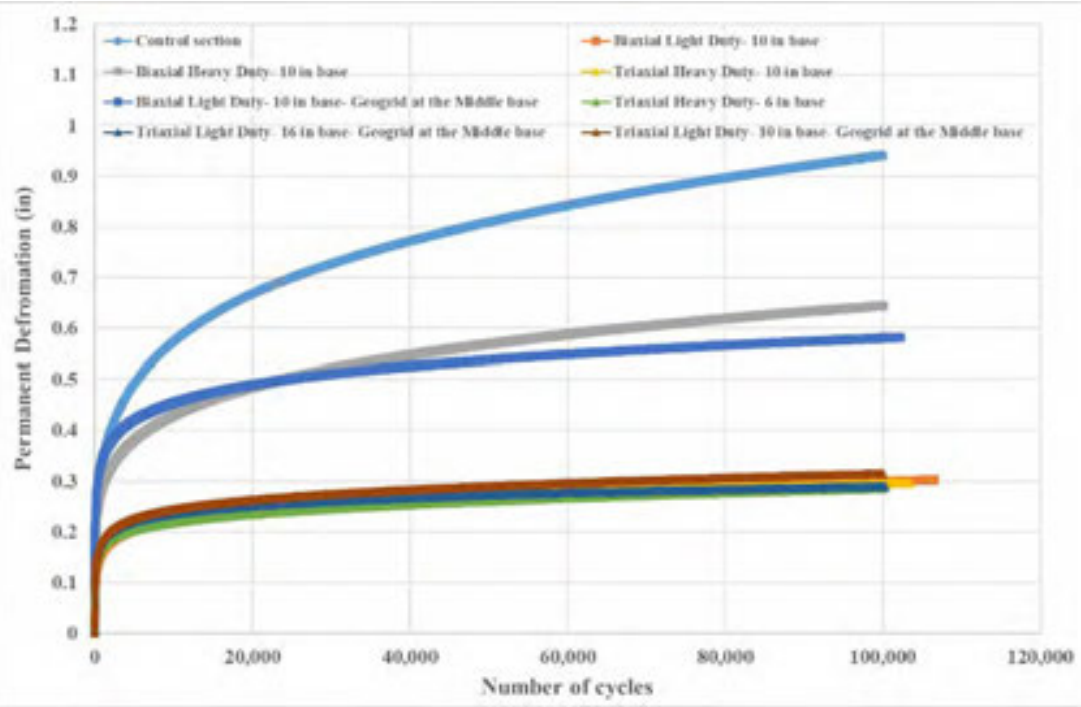

Figure 7. Permanent deformation for Biaxial geogrids and Triaxial geogrids
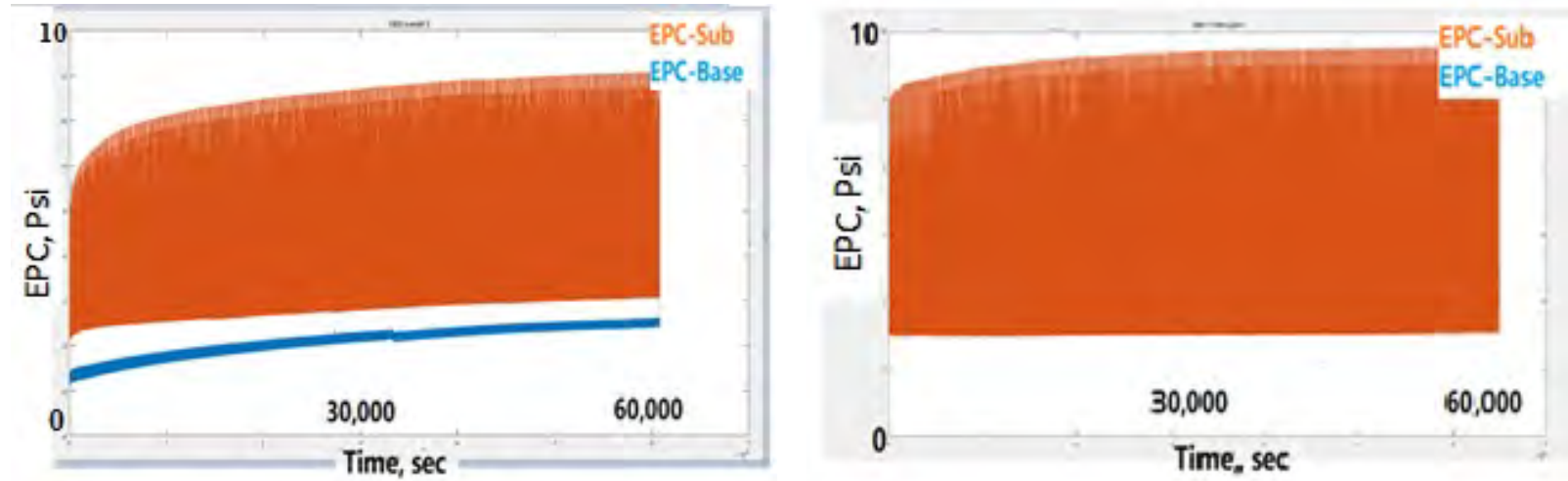

a)

b)
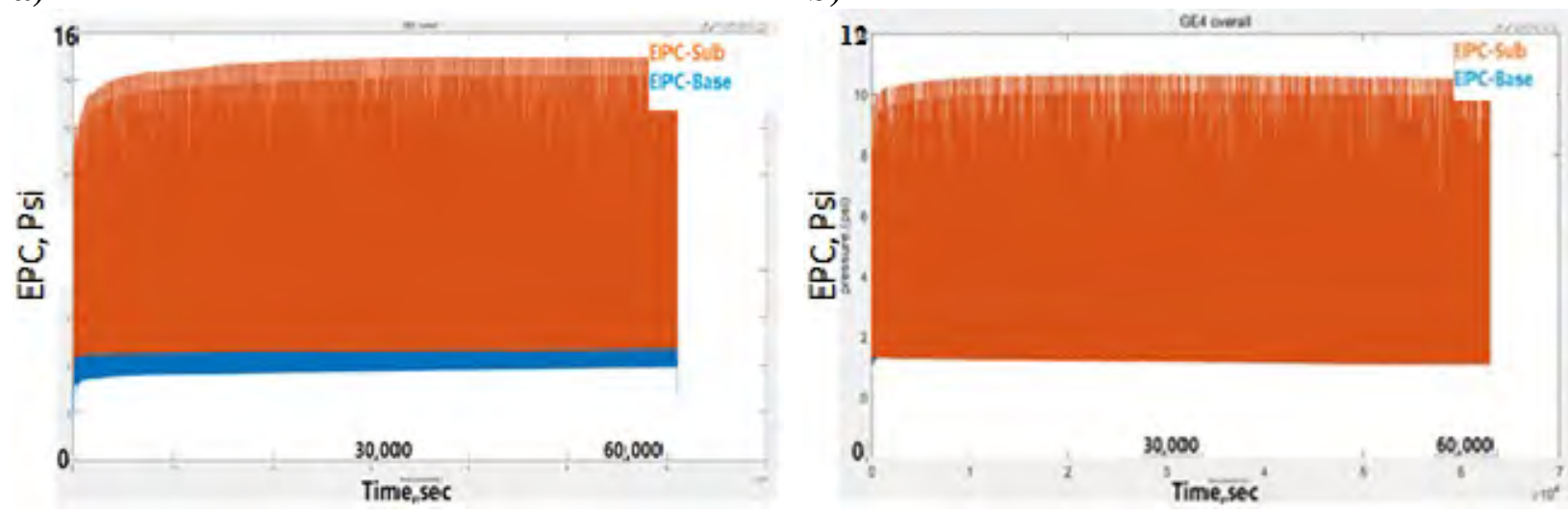

c)

d) 


\section{(冈ㅛ Geosynthetics Conference}
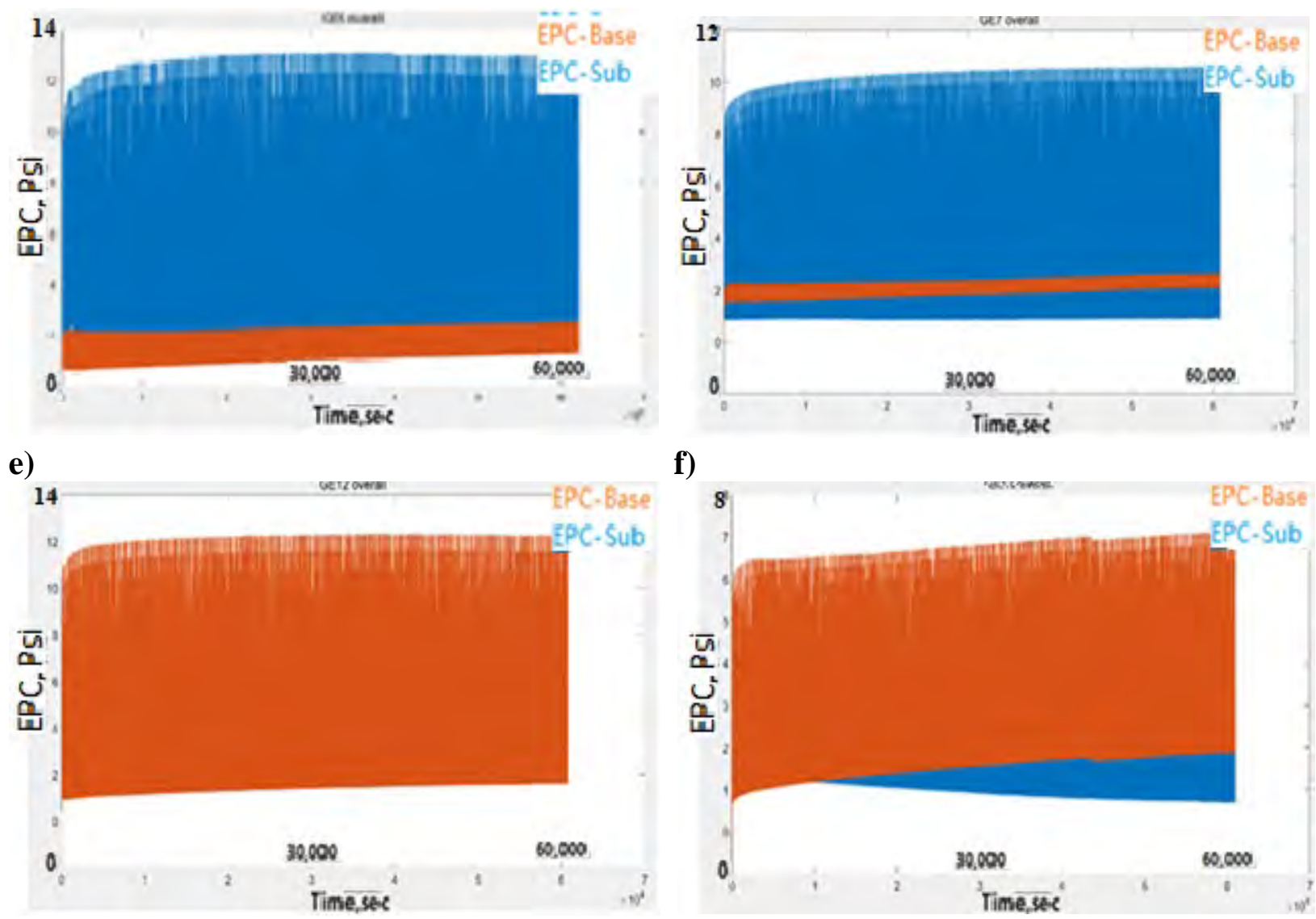

g)

h)

\section{Figure 8. Pressure cells result for sections a) GE0, b) GE1, c) GE2, d) GE4, e) GE5, f) GE7, g) GE12, and h) GE15}

\section{CONCLUSIONS}

In this study, a series of large-scale laboratory tests were conducted to determine the geogrids' effectiveness under various parameters. These parameters include the types of geogrid, the aperture of the geogrid, the geogrid's stiffness, the location where to install the geogrid, and the thickness of the base course layer. After plotting and comparing the results, the following preliminary observations can be made:

- From the permanent deformation versus the number of loading cycles plot, it can be stated that the deformation of the control section without the geogrid reaches almost one-inch at the end of the test; however, the triaxial and biaxial geogrid reinforced section deformation curves show the maximum deformation around 0.25 and 0.5 inches respectively which is almost one quarter and half of the unreinforced section deformation. Generally, it can be stated that triaxial geogrid perform better than biaxial geogrid in decreasing permanent deformation of the pavement.

- The test sections with the heavy-duty geogrid always have higher-pressure cell readings than the light-duty geogrid. Also, since the heavy-duty geogrid having a higher stiffness 


\section{(쇼 Geosynthetics Conference}

than the light-duty geogrid, the high-strength geogrid can provide more confinement pressure as well.

- For the overall earth pressure cell results, except for GE4 and GE7, the test sections have similar trends: the earth pressure cell data was increasing as the loading occurred, both in the subgrade and base course layer, but the increasing rate and magnitude are higher in base course layer than the subgrade layer. This evidence supports that the geogrids can stabilize both the subgrade and the base course layer, but more in the base course. GE4 and GE7 have a converse result, and the reason could be caused by the geogrid location.

- The average earth pressure cell data in triaxial geogrid tests is higher than the biaxial geogrid tests. The comparison between test section GE1 and GE4 on the earth pressure cell data overall shows that under the same location and same thickness of the base course layer, the pressure in section GE4 in the base course is at least two psi higher than the pressure in the section GE1 on top of subgrade layer. The triaxial geogrid would have more effectiveness than the biaxial.

\section{ACKNOWLEDGEMENTS}

This manuscript is based upon work supported by the Minnesota Department of Transportation (MnDOT) under contract number 1034932 entitled "Effectiveness of Geotextile/Geogrids in Roadway Construction; Determine a Granular Equivalent (G.E.) Factor". The authors thank MnDOT for this support. The contents and views in this paper are those of the authors and do not necessarily reflect those of the funding agency.

\section{REFERENCES}

Abu-Farsakh, M. Y., and Chen, Q. (2011). "Evaluation of geogrid base reinforcement in flexible pavement using cyclic plate load testing." International Journal of Pavement Engineering, 12(3), 275-288.

Al-Qadi, I. L., Brandon, T. L., Valentine, R. J., Lacina, B. A., and Smith, T. E. (1994). "Labtatory evaluation of geosynthetic-reinforced pavement sections.” Transportation Research Record, 1439.

Al-Qadi, I. L., Dessouky, S., Tutumluer, E., and Kwon, J. (2011). “Geogrid mechanism in lowvolume flexible pavements: Accelerated testing of full-scale heavily instrumented pavement sections.” International Journal of Pavement Engineering, 12(2), 121-135.

Alimohammadi, H., Schaefer, V. R., Zheng, J., and Li, H. (2020a). "Performance evaluation of geosynthetic reinforced flexible pavement: a review of full-scale field studies.” International Journal of Pavement Research and Technology.

Alimohammadi, H., Zheng, J., Buss, A., Schaefer, V. R., Williams, C., and Zheng, G. (2020b).

"Field and simulated rutting behavior of hot mix and warm mix asphalt overlays."

Construction and Building Materials, Elsevier, 265, 120366.

Alimohammadi, H., Zheng, J., Schaefer, V. R., Siekmeier, J., and Velasquez, R. (2020c).

"Performance Evaluation of Geogrids in Flexible Pavement: A Review of Large-Scale Laboratory Studies.” Transportation Geotechnics.

Cuelho, E. V., and Perkins, S. W. (2017). “Geosynthetic subgrade stabilization - Field testing 


\section{(쇼 Geosynthetics Conference}

and design method calibration.” Transportation Geotechnics, Elsevier Ltd, 10, 22-34.

Han, J., Zhang, Y., and Parsons, R. L. (2008). "Development of a Performance-Based

Laboratory Test Method for Evaluating Geosynthetic-Soil Confinement."

Ingios Geotechnics. (2020). "Integrated Mobile Accelerated Test System.” https://www.ingios.com.

Qian, Y., Han, J., Pokharel, S. K., and Parsons, R. L. (2013). "Performance of triangular aperture geogrid-reinforced base courses over weak subgrade under cyclic loading.” Journal of Materials in Civil Engineering, 25(8), 1013-1021.

Saghebfar, M., Hossain, M., and Lacina, B. A. (2016). "Performance of geotextile-reinforced bases for paved roads.” Transportation Research Record, 2580(2580), 27-33.

Siekmeier, J., and Casanova, J. (2016). "Geogrid Reinforced Aggregate Base Stiffness for Mechanistic Pavement Design.” Minnesota Department of Transportation, Report No. MN/RC 2016-24.

Zornberg, J. G. (2017). "Functions and Applications of Geosynthetics in Roadways." Procedia Engineering, Elsevier Ltd, 298-306.

Zornberg, J. G., and Gupta, R. (2010). "Geosynthetics in pavements: North American contributions." 9th International Conference on Geosynthetics - Geosynthetics: Advanced Solutions for a Challenging World, ICG 2010, (December 2016), 379-400. 